\title{
CRITERIA FOR ENVIRONMENTAL OPTIMIZATION OF ELECTRICAL AND THERMAL ENERGY IN AGRO-TOURISM
}

\author{
RAMONA GIUREA $^{1,2}$, ILARIA PRECAZZINI ${ }^{1}$, MARCO RAGAZZI $^{1} \&$ MOISE IOAN ACHIM $^{3}$ \\ ${ }^{1}$ University of Trento, Department of Civil Environmental and Mechanical Engineering, Trento, Italy \\ ${ }^{2}$ University "Lucian Blaga" of Sibiu, Department of Industrial Engineering and Management, Sibiu, Romania \\ ${ }^{3}$ University 1 Decembrie 1918 of Alba Iulia, Department of Exact Sciences and Engineering, Alba Iulia, Romania
}

\section{ABSTRACT}

Electrical and thermal energy optimization is a topic that concerns many sectors. The present article analyses the different technologies that can be used in buildings in order to integrate thermal and electrical energy requirements with renewable sources. The attention is particularly focused on the agro-tourism sector and the various solutions, concerning above all the use of biomass and solar energy, are proposed to increase the environmental sustainability of these kind of structures.

Keywords: agro-tourism, electrical energy, optimization, sustainability, thermal energy.

\section{INTRODUCTION}

Tourism is the third most significant socio-economic activity in the European Union (EU) [1]. According to the World Tourism Organization (UNWTO), in terms of worldwide export category, tourism reaches the third position following fuels and chemicals sector and preceding food and automotive production. In many developing countries, tourism has achieved even the first place in export sector [2]. Number of overnight stays in various type of accommodation for tourists, provides information about the length of stay and the number of visitors, these data are considered a key indicator for tourism statistics [3]. According to Eurostat data, in 2014 visitors spent 2.68 billion nights in EU-28 [4], tourist accommodation and these numbers pointed out an $1.5 \%$ increase compared with the same data concerning the year 2013 (considering similar rates of change for both residents and non-residents) [3].

Agro-tourism is a part of this sector; this relatively new proposal for tourists includes various activities, such as accommodations (rooms, apartments, rural housing, farm campsite), breakfast and restaurant service, leisure activities (laboratories for children and families, farm visits, outdoor sports, horse-riding) [5]. According to Eurostat data [6], rural localities as destination in Europe represented a percentage close to $45 \%$ of the total nights spent by tourists. In Romania and Italy, agro-tourism is starting to develop. In Italy, rural areas and farms are involved in a program of development through diversification into new activities such as agro-tourism [7], whereas Romania, beginning from 1989, after the communist period, started to implement legislation in tourism sector [8].

Rural tourism has grown rapidly since 1970 by responding to new markets and development opportunities. Quality tourism criteria have changed: one of the most important aspects that travellers are searching for is the positive environmental impact [9]. Tourism in general can produce significant pressures and impacts on the environment, for this reason sustainability in this sector is particularly significant [10].

The EU promotes the use of energy from renewable sources according to the EU Renewable Energy Directive (RED) [11]. In 2012, in the conclusions of the Commission's Communication on renewable energy [12], the Council acknowledged the need to consider the sustainability dimensions of the use of biomass resources [13]. 
The use of biomass - particularly wood and wood waste [11] - gives a key contribution to the European renewable energy target of $20 \%$ by 2020 [14]. A sustainable use of biomass can play an important role in the fight against climate change and contributes to economic growth and employment, particularly in rural areas [15].

Biomass is considered carbon neutral since the carbon released when solid biomass burns had been previously absorbed during the tree growth. The use of biomass for power generation is supported by incentives [15].

The increasing use of biomass as fuel, particularly in manual devices, has produced high PM emissions [16]. The particulate matter production is related to a low-quality combustion due to the quality of the biomass (especially the amount of humidity) and to the regulation of the combustion process.

As to the electricity from renewable sources, in Italy, incentive systems for RES-E (Renewable Energy Sources to Electricity) are managed by the "Gestore dei Servizi Energetici" (GSE - Manager of Electricity Services). The production of electricity from renewable sources is mostly promoted through economic advantages: premium tariffs, feedin tariffs and tender schemes. There are also tax regulation mechanisms for investment in RES-E plants. GSE manages renewable energy's sale on request and interested parties can make use of net-metering. Grid operators have to give priority to renewable energy plants in term of accessibility and dispatchment. Plant operators can request the grid operator to expand the grid if this is necessary in order to connect a plant [17]. In Romania instead, electricity from renewable sources is mainly promoted by a quota system. In 2016, the financial support scheme for new installations producing electricity from renewable sources ceased. After 2014, the heavy financial losses of the producers caused a diffused discontent with the development of the RSE-E market. However, according to the 2016 version of the Romanian National Energy Strategy, there are no plans for a further support scheme for new installations except that concerns the underdeveloped biomass sector [18].

\section{OVERVIEW OF THE AGRO-TOURISM SECTOR}

Energy requirements that allow satisfying the heating of the agro-touristic structures depend heavily on the climatic conditions of the location where the agro-tourism is located, moreover exposure to the direct sunlight and the thermal insulation of the building have a significant role. The energy load requested for the preparation of hot water is mainly determined by users' habits and the amount of this load can undergo strong oscillations.

As well as residential buildings, in agro-tourisms the heating of environments and the production of hot water represent the most important energy requirements of the structure. In rural and mountain contexts, in Italy as well as in Romania, heating is guaranteed mainly through boilers or heat pumps, the energy load can be integrated with solar thermal panels; this solution is diffused particularly in recently built or refurbished structures with low temperature heating systems. In addition to the previously mentioned technologies, woody biomass stoves are particularly diffused, these are positioned especially in kitchens and common areas.

Hot water production is ensured by boiler or heat pumps.

Since energy needs are significant, especially in case of agro-touristic structures with poor thermal insulation, it is essential to use measures in order to minimize dispersions such as giving specific instructions to those people working in the accommodation. These recommendations concern the switching off of heating or cooling devices when rooms are empty or telling guests to lower and close shutters to limit thermal dispersions during evening and night and to reduce, during the winter season, windows' opening to the sufficient time in order to ensure the change of air. 
Concerning this, installation of automatic deactivation systems that turn off heating or cooling devices when windows are open, would ensure greater security.

In order to guarantee the best comfort conditions, depending on guests' demands, it is preferable that rooms or accommodations are provided with independent thermostats or thermostatic valves applied to the radiators, so as to regulate the heating or cooling systems. These devices certainly involve complications in the installation system but they allow at the same time to adjust the temperature depending on the need in the different spaces (i.e. bathrooms, bedrooms or kitchens). This makes it possible to create good comfort conditions and to avoid to warm useless rooms.

In the electricity sector, as well as for thermal energy requirements, it is crucial to act first by reducing the energy demand required by the building and only later the electrical requirements can be integrated with on-site production from renewable sources, for example through solar photovoltaic technology.

As regards the electric consumptions, the use of energy saving lighting systems and household appliances, automatic lighting systems, sensors or timers, the adoption of magnetic cards to enable and disable the power supply in the rooms or accommodations, together with a responsible use of lighting and devices, allow to reduce the electrical consumption of the structure.

In case of replacement or purchase of new household appliances, it is important to choose the ones characterized by high energy efficiency since even if they have a higher initial cost, they can produce energy savings over the years of use.

As to the possibility of using electricity from renewable sources, energy suppliers offer contracts that guarantee to supply electricity produced by renewable energy sources; these contracts can substitute the investment in photovoltaic panels. In any case, renewable sources are aimed at reducing the use of traditional fuels and consequently the climate changing emissions associated with their combustion.

Wood combustion for energetic purposes is a still widespread practice, woody biomass as fuel is diffused above all in rural and mountain areas with conifer and broad-leaved forests. This type of biomass is used to feed various types of appliances; it can be used in simple and ancient stoves as well as in modern and advanced technologies including also boilers.

Although the use of biomass is stimulated and suggested since being a renewable source with neutral $\mathrm{CO}_{2}$ production, biomass combustion can anyway generate significant polluting emissions. The process that involves solid fuels reaches actually the correct combustion conditions with much more difficulties unlike gas or liquid fuels that are already present or can be easily carried out in the gaseous phase, necessary for the combustion process to take place.

The use of biomass for household energy production is favoured since woody biomass is diffused and simply available. In any case, the pollution associated with the biomass combustion depends on the technological devices in term of efficiency and correct use of the device as well as on the quality of the biomass.

Depending on the adopted technology (i.e. stoves, boilers, etc.), biomass can be used in form of pieces of wood, pellet or chips, although in many cases the use of chopped wood is favoured by the possibility of autonomous supply.

The use of wood chips as fuel for boilers could be significant in case of agro-touristic structures with considerable quantities of waste woody biomass, as result of the agricultural activities.

The technological progress over the years has developed the production of combustion devices with better energy yields and quality of the combustion process. 
Wood or pellet stoves can be directly installed in rooms (i.e. they are frequently present in kitchens or living rooms) and they mainly heat spaces by convection; they are easy to install since they do not require recirculation of heat transfer fluid but they offer a low thermal inertia. Devices working with convection generate air movements with significant vertical temperature gradients that can affect the comfort conditions.

Tiled stoves are on the contrary a particular type of stoves that work with irradiation, thanks to their significant mass. These devices are able to store the heat produced during combustion, and to release it gradually even when the combustion process is finished. This technology requires only one or two daily charges and it offers good energy efficiency with low pollutant emissions. These stoves are realized in order to allow a rapid combustion with intense blaze so as to exploit the calorific value of the fuel.

The high temperatures generated in the combustion chamber of this type of stoves, can reach $700-800^{\circ} \mathrm{C}$; these conditions can allow wood gasification and then the complete combustion. This type of process can reach high yields (more than 90\%) and reduce pollutant emissions. This more complete combustion process causes less dirty residues in the stoves and in the chimney [19].

This kind of stoves work mainly thanks to irradiation; this process is therefore characterized by limited air movements so that it allows a good level of comfort conditions; this advantage is particularly significant for buildings with stone walls where it is possible to achieve a more homogeneous heating.

This technology presents a significant weight, for this reason it's necessary to consider properly the additional load over the floor when choosing this type of device, so as not to exceed the maximum capacity of the floor. In some cases, the load due to the tiled stoves can be incompatible with the structural capacity of the floor.

All biomass-powered devices require proper installation by qualified technicians; it is also fundamental to clean and check the appliance (stove and chimney flues) and to do the routine maintenance operations in order to avoid malfunctions with serious consequences such as gas poisonings and fires.

It's better to do devices' revision and maintenance before the winter season or before the period of frequent use of the appliance. In addition to this, each device requires specific management and maintenance operations; these practices are necessary in order to ensure a safe combustion process and good energy performances.

Chimney flues play an important role in biomass-fed systems in order to ensure good working conditions. Flues have to be able to evacuate exhaust fumes and ensure seal, they have to be insulated and waterproof to avoid heat dispersions and condensation phenomena. They have also to be adequately separated from combustible or flammable materials.

Heating and hot water production in agro-touristic structures are guaranteed in most of the cases by boilers. In this sector, in Italy as well as in Romania, at the beginning the old gas boilers with atmospheric burner, on/off control and the presence of pilot flame had a low average yield (60\%). Modern condensing technologies, thanks to various adjustments, reach higher average yields. New boilers are characterized by better thermal insulation, good thermal exchange efficiency' surfaces, the number of ignition and turning off is limited and exhaust gases are discharged at lower temperature in order to recover residual heat. New devices can also reduce the amount of excess air of combustion without increasing the polluting emissions' production.

The heat pump is a device that, thanks to the supply of work, allows increasing the available energy's temperature so as to return this energy with a temperature useful for heating environments. The performance of these devices is evaluated through the 
performance coefficient, which indicates the relationship between the useful result of the machine and the input energy needed to obtain it.

From the energetic point of view, the heat pump allows a very efficient energy use since the thermal energy obtained is greater than the electric consumptions requested for the machine's working.

Heat pumps [21], work using low temperature thermal absorption and they transfer the absorbed heat to a higher thermal level; this is possible working at two different pressures so as to exploit the liquid-vapour phase change of the refrigerant.

This type of machine performs the evaporation of the refrigerant subtracting heat to the cold source working at consistent pressure and temperature, the device delivers then the absorbed heat through the condensation process operating at a higher pressure and consequently at a temperature useful for heating.

Heating terminals are related to the type of heat generators used in the building; radiators were the systems traditionally used in the past, in new or refurbished buildings ceiling, floor or wall heating systems and fan heaters are also diffused.

In case of existing installations with radiators, it is important that they are not covered with curtains or furniture that obstruct the convective air flow. If they are positioned under the windows, it is advisable to place an insulating material between the wall and the radiator in order to avoid heat losses as the walls where the radiators are positioned are thinner.

Radiators are characterized by a reduced thermal inertia compared to radiant floor heating but the first allow reaching faster the desired temperature in the rooms even when these are discontinuously used.

There were important changes over time: energy required by hot water production has grown in percentage as to the total consumption. This is due to the better thermal insulation of buildings. The demand for sanitary hot water supply, unlike heating, depends mainly on the users' habits, whereas the dependence on the 'heating degree days' of the place is not important. Hot water preparation can be done through various types of boilers or heat pumps. These technologies can also be integrated with solar thermal panels in order to exploit renewable energies.

Hot water quantity requirements can be guaranteed through instantaneous boilers or storage tanks.

Instantaneous boilers work producing hot water only when it's requested, with this type of functioning water is warmed to the desired temperature passing through a heat exchanger. As long as there is warm water's request the heating function is excluded.

This kind of functioning requires frequent boiler ignition and the hot water requests last short periods of time with negative consequences on the energy efficiency. Moreover, instantaneous boilers warm the water from the temperature of the water distribution systems to the desired one; this requires a significant thermal power and as consequence of this, boilers need to have greater power than the one required to ensure heating of the environments.

Compared to instantaneous hot water production systems, the use of a storage tank reduces the boiler's ignition and makes it possible to use boilers with lower thermal power fulfilling the same requests. The accumulation systems allow also to abandon the on/off functioning and the working becomes more continuous and regular; this brings benefits in term of performance and polluting emissions. The use of a storage tank is also required in presence of solar thermal panels or when there are heat pumps or biomass boilers.

The possibility to accumulate thermal energy is a particularly important issue when using renewable sources such as solar thermal energy. Solar energy's availability is actually not predictable, and its presence does not always correspond to the requests. 
Storage tank's size is mainly due to the daily consumption of hot water and to the concentration of this demand. It is also crucial the presence of a good thermal insulation and the possibility of ensuring thermal layering within this. The absence of thermal stratification activates the heat supply by the boiler or the heat pump, which warms the entire storage precluding the possibility of exploiting the energy absorbed through solar collectors.

With regard to the electricity demand, the possibility to use the photovoltaic technology [22], is a way to cover part of the electrical consumption with a production from renewable sources. In these cases, the use of photovoltaic panels is not due to the absence of a connection to the power grid rather to the choice of an on-site energy production. The self-produced electricity consumption also eliminates distribution losses. Photovoltaic system's productivity and the convenience of this type of choice depend first of all on the geographic position of the building in terms of solar radiation availability during the year; there's also a significant dependence on orientation, roof inclination and global yield of the system, taking into account also the quality of the components.

Photovoltaic panels can satisfy a significant part of the annual electrical demand if the installation has been correctly dimensioned taking into account the specific electrical consumption during the year.

Inverters are needed, as photovoltaic modules produce direct current (DC) which has to be converted into alternating current (AC) with a frequency of $50 \mathrm{~Hz}$ in order to be used in the building or to be transferred to the power grid; this amount of energy is registered through a counter.

Photovoltaic panels can be installed over the roof in an integrated way, for example if this operation is carried out during the roof's rebuilding or they can be placed over the roof; alternatively, panels can be installed on car parks or terraces' roofs.

Given that in most of the cases the touristic inflow to the agro-tourisms is mainly concentrated during the summer months, photovoltaic technology allows providing the highest energy production, taking anyway into account the local weather conditions.

Although the building's lighting is responsible for a limited fraction of the global energy consumption, in comparison with the energy requested for heating, it is however possible to achieve energy savings even in this sector as lighting technologies and systems are often not efficient.

Depending on the kind of lamps installed in the building, there can be significantly changes in the energy consumption as well as in terms of quality and quantity of produced light.

The use of high performance energy-saving lighting devices, as well as being quick to turn on, they can produce environmental benefits as modern bulbs have lower energy consumption than the bulbs traditionally used in the past and in addition to this, the modern ones have much longer working life.

The choice of lighting devices has to take into account the requirements related to the type of activities carried out in the different rooms in which they have to be positioned and the daily working hours.

In this paper, indirect role of agro-tourism structures in the energy sector has not been taken into consideration (i.e. food waste source separation aimed to biogas production in a centralised plant [23] and residual municipal solid waste valorisation in waste to energy plants [24]).

\section{CONCLUSIONS}

In order to make the best use of the various mentioned technologies, especially those that allow using solar energy such as thermal and photovoltaic panels, it is necessary to be able 
to reduce significantly the amount of energy requirements of the structure. By this way, an important fraction of the demand can be satisfied using renewable sources so as to avoid traditional fuels' use. When the energy requirement is reduced, it's possible to use renewable energies without excessive oversizing.

The possibility to exploit renewable energies needs a synergy between a good thermal insulation of the building, the presence of suitable heating terminals (preferably those functioning at low temperature) and a well dimensioned and isolated hot water storage tank. Considering individually the different technologies, they present advantages and disadvantages; the best choice is to combine the various solutions in order to make it possible to use several energy sources favouring the renewable ones.

Economic and environmentally advantages and benefits are significant according to amount of the global requirements that can be satisfied through renewable energies.

\section{REFERENCES}

[1] European Parliamentary Research Service, Major challenges for EU tourism and policy responses, http:/www.europarl.europa.eu/RegData/etudes/BRIE/2017/ 603932/EPRS_BRI(2017)603932_EN.pdf, Accessed on: 2 Jun. 2017.

[2] World Tourism Organization (UNWTO), UNWTO Tourism Highlights 2016 Edition, http://www.e-unwto.org/doi/pdf/10.18111/9789284418145, Accessed on: 2 Sep. 2016.

[3] European Union, Statistical books - Eurostat regional yearbook, 2016 Edition, http://ec.europa.eu/eurostat/documents/3217494/7604195/KS-HA-16-001-ENN.pdf/76c007e9-6c1d-435a-97f8-e5ea700aa149, Accessed on: 5 Sept. 2017.

[4] European Union, Glossary: EU enlargements, http://ec.europa.eu/eurostat/statisticsexplained/index.php/Glossary:EU-28, Accessed on: 2 Jun. 2016.

[5] European Parliamentary Research Service, Farm diversification in the EU, 2016, http://www.europarl.europa.eu/RegData/etudes/BRIE/2016/581978/EPRS_BRI(2016 )581978_EN.pdf, Accessed on: 3 Jun. 2016.

[6] European Union, Eurostat Statistics Explained, Tourism statistics at regional level, http://ec.europa.eu/eurostat/statisticsexplained/index.php/Tourism_statistics_at_regio nal_level, Accessed on: 2 Sep. 2016.

[7] European Commission, Agriculture and rural Development Italy, https:/ec.europa.eu/ agriculture/sites/agriculture/files/cap-in-your-country/pdf/it_en.pdf, Accessed on: 5 Oct. 2016.

[8] Autoritatea Nationala pentru Turism (ANT), http://turism.gov.ro/legislatie/, Accessed on: 10 Jan. 2017.

[9] European Parliament, Industrial Heritage and Agri/Rural Tourism in Europe, http://www.europarl.europa.eu/RegData/etudes/etudes/join/2013/495840/IPOLTRAN_ET(2013)495840_EN.pdf, Accessed on: 7 Oct. 2016.

[10] European Parliament, Sustainable tourism. The environmental dimension, http://www.europarl.europa.eu/RegData/etudes/BRIE/2017/599327/EPRS_BRI(2017 )599327_EN.pdf (2017), Accessed on: 2 Apr. 2017.

[11] EU Renewable Energy Directive http://eur-lex.europa.eu/legalcontent/EN/ALL/?uri=CELEX:32009L0028, Accessed on: 12 Jan. 2017.

[12] European Commission, Renewable Energy: a major player in the European energy, market, http://eur-lex.europa.eu/legal-content/EN/ALL/?uri=CELEX:52012DC0271, Accessed on: 10 Jan. 2017. 
[13] Council of the European Union, Council conclusions on Renewable Energy, http://www.consilium.europa.eu/uedocs/cms_data/docs/pressdata/en/trans/ 133950.pdf, Accessed on: 15 Dec. 2016.

[14] European Union, Eurostat - Statistics in focus, renewable energy, http://epp.eurostat.ec.europa.eu/cache/ITY_OFFPUB/KS-SF-12-044/EN/KS-SF-12044-EN.PDF, Accessed on: 15 Dec. 2016.

[15] European Parliament, Biomass for electricity and heating - Opportunities and challenges, http://www.europarl.europa.eu/RegData/etudes/BRIE/2015/568329/EPRS_BRI(2015 )568329_EN.pdf (2015), Accessed on: 15 Dec. 2016.

[16] European Commission, European Environment Agency, The EU Environmental Implementation Review Country Report http://ec.europa.eu/environment/eir/pdf/report_it_en.pdf, Accessed on: 4 Feb. 2017.

[17] RES LEGAL Europe- regulations on renewable energy generation -Italy, http://www.res-legal.eu/search-by-country/italy/, Accessed on: 2 Mar. 2017.

[18] RES LEGAL Europe- regulations on renewable energy generation -Romania, http://www.res-legal.eu/search-by-country/romania/, Accessed on: 2 Mar. 2017.

[19] QualEnergia, Riscaldarsi con il pellet e con la legna (in Italian), http://www.qualenergia.it/, Accessed on: 17 Jan. 2016.

[20] Casa\&Clima, Efficienza energetica negli impianti di riscaldamento

[21] Lazzarin R., Pompe di calore: parte teorica, parte applicativa (in Italian), 2010

[22] Renovo - Tecnologie energetiche, http://renovo-te.it/home/impianti-di-riscaldamento/, Accessed on: 17 Jan. 2017.

[23] Rada, E.C., Effects of MSW selective collection on waste-to-energy strategies, WIT Transactions on Ecology and the Environment, 176, pp. 215-223, 2013.

[24] Rada, E.C., Present and future of SRF, Waste Management, 47, pp. 155-156, 2016. 